\title{
Pressurized $\mathrm{CF}_{3} \mathrm{I}-\mathrm{CO}_{2}$ Gas Mixture under Lightning Impulse and its Solid By-Products
}

\author{
M. S. Kamarudin' ${ }^{1}$, A. Haddad ${ }^{2}$, B. C. Kok ${ }^{3}$, N. A. M. Jamail ${ }^{4}$ \\ ${ }^{1,3,4}$ Faculty of Electrical \& Electronic Engineering, Universiti Tun Hussein Onn Malaysia, Malaysia \\ ${ }^{2}$ School of Engineering, Cardiff University, United Kingdom
}

\section{Article Info \\ Article history: \\ Received Apr 30, 2017 \\ Revised Sep 27, 2017 \\ Accepted Oct 11, 2017}

\section{Keyword:}

By-products

$\mathrm{CF}_{3} \mathrm{I}$

Gas mixtures

Lightning impulse

$\mathrm{SF}_{6}$

\begin{abstract}
This paper describes tests results on the $\mathrm{CF}_{3} \mathrm{I}-\mathrm{CO}_{2}$ gas mixtures as an alternative for $\mathrm{SF}_{6}$ gas as to be used as insulating medium in high voltage applications. Pressurized $\mathrm{CF}_{3} \mathrm{I}-\mathrm{CO}_{2}$ gas mixtures are subject under standard lightning impulse voltages at both positive and negative polarities. Under rod-plane configuration, the electrode gap length and gas pressure are varied accordingly. Upon completion of the laboratory tests, SEM and EDX analyses are carried out to assess the solid by-products. It was found that higher gas mixtures provide better insulation strength. In terms of weight, $50 \%$ of the solid by-product is found to be iodine.
\end{abstract}

Copyright $\left({ }_{0} 2017\right.$ Institute of Advanced Engineering and Science. All rights reserved.

\section{Corresponding Author:}

M. S. Kamarudin,

Faculty of Electrical \& Electronic Engineering,

Universiti Tun Hussein Onn Malaysia,

Parit Raja, 86400 Batu Pahat, Johor, Malaysia.

Email: saufi@uthm.edu.my

\section{INTRODUCTION}

$\mathrm{SF}_{6}$ is until now regarded as the best gas insulation medium for high voltage applications. However, many studies show that SF6 greenhouse effects raise concerns to its environmental impact. It is not easily decomposed in atmosphere, and its emission will highly affect the environment. Also, its global warming potential (GWP) is the highest among all available gases, and its production is now restricted under Kyoto Protocol. For these reasons, the usage of SF6 has to be reduced, and eventually replaced. This scenario has prompt for a lot of investigations on alternative gases or gas mixtures. Fundamental insulation characteristics, such as voltage-time $(V-t)$ characteristics, current interrupting capability, thermal conductivity and breakdown strength are investigated and presented by a lot of researchers [1-5].

Trifluoroiodomethane $\left(\mathrm{CF}_{3} \mathrm{I}\right)$ is one of the alternatives proposed for replacing $\mathrm{SF}_{6}$ [6]. However, due to its high boiling property, $\mathrm{CF}_{3} \mathrm{I}$ is mixed with other gases, such as $\mathrm{CO}_{2}$ or $\mathrm{N}_{2}$. As mixing with other gases will likely reduce the insulation properties of pure $\mathrm{CF}_{3} \mathrm{I}$, a lot of tests have to be carried out before the gas can be fully adopted as the main insulating medium in high voltage equipment.

\section{RESEARCH METHOD}

This section describes the experimental setup used in the research and also the measurement techniques adopted in order to obtain accurate data for the study. 


\subsection{Experimental Setup}

The section describes the generation of lightning impulse, gas filling and removal system, as well as electrode geometry and configuration.

\subsubsection{Lightning Impulse Generation}

Standard 1.2/50 lightning impulse is generated by an impulse generator, which capable of producing impulses as high as $400 \mathrm{kV}$. A 50ns rise time capacitive divider was used for impulse voltage measurement. Other measurement equipment includes a digital storage oscilloscope, humidity sensor, and temperature sensor.

\subsection{2. $\quad \mathrm{CF}_{3}$ I Gas Filling and Removal System}

In order to ensure no gas will be released into the atmosphere, a reliable and leakproof system has to be in place. To realize this reason, a gas filling and removal system made by DILO is used in the experimental setup. The system includes a filter, a compressor, and a vacuum compressor to store the gas in specially-designated gas cylinders.

\subsubsection{Electrode Geometry and Configuration}

Rod-plane electrode configuration is used in this study. The tip diameter of the rod electrode is $1 \mathrm{~mm}$, while for plane electrode, the diameter is $90 \mathrm{~mm}$, with $5 \mathrm{~mm}$ radius around its edge. All electrodes are made from brass. The surfaces of the electrodes are mirror finished, to ensure no effect from protrusion which may compromise the test results. The rod electrode is connected to the high voltage supply, while the plane electrode is grounded. To represent various field uniformities, the gap distance between the electrodes can be varied. To achieve this, the ground electrode is vertically moveable in order to achieve the desired gap length. The movement of the ground electrode is controlled by an outside laptop, connected with cable through a compression seal fitting. Using this system, the electrode gap distance can be varied without the need to remove the gas inside the pressure vessel.

\subsection{Measurement Techniques}

This section describes the standard measurement techniques adopted in the experimental study, as well as simulation technique to model the setup.

\subsection{1. $\quad 50 \%$ Breakdown Voltage}

For this test, $\mathrm{U}_{50}$ for $\mathrm{CF}_{3} \mathrm{I}-\mathrm{CO}_{2}$ gas mixtures are obtained as according to the Standard [7]. The upand-down method is used to determine $\mathrm{U}_{50}$ by applying at least 20 impulse shots at a timed interval of 120 seconds.

\subsubsection{Maximum Electric Field}

COMSOL Multiphysics version $4.3 \mathrm{a}$ is used to carry out the modelling and electric field computations. The modelling is simplified into a two-dimensional (2D) model instead of a full threedimensional (3D) model. Even though it is in a 2D model, the accuracy of the simulation results will not be affected. By adopting this technique, memory and processing time will be saved. Axis-symmetric features are used to simplify further the model without affecting the simulation results.

\section{EXPERIMENTAL RESULTS}

In an effort to investigate the effect of gas pressure on the insulation performance of $\mathrm{CF}_{3} \mathrm{I}-\mathrm{CO}_{2}$ gas mixtures used in this study, only the rod-plane electrode configuration is used for that purpose. This is to ensure that, for all gas pressures, tests that are carried out on the gap length between the electrodes can be extended to the maximum allowable length, while keeping the impulse voltage level at a safe value for the bushing.

As for this test, apart from 1.0bar (abs) of $\mathrm{CF}_{3} \mathrm{I}-\mathrm{CO}_{2}$ pressure which has been used in previous studies, the pressure is increased to 1.5bar (abs) and 2.0bar (abs). According to Dalton's Law, the partial pressure of each $\mathrm{CF}_{3} \mathrm{I}$ and $\mathrm{CO}_{2}$ gas mixture is shown in Table, placed according to the corresponding total pressure of the gas mixtures.

Tests were carried out with both positive and negative impulse polarities in a rod-plane electrode configuration. The results are plotted in Figure 1 and Figure 2 across various electrode gap lengths and gas pressures.

Referring to Figure 1, as expected under a rod-plane configuration, $\mathrm{U}_{50}$ for the negative impulse is much higher than for the positive impulse. This is true for all pressures. It can be said that the $\mathrm{U}_{50}$ increases 
with the pressure of the $\mathrm{CF}_{3} \mathrm{I}-\mathrm{CO}_{2}$ gas mixture. Careful examination of the difference between 1.0bar (abs) with 2.0bar (abs) under a negative impulse reveals that there is an almost constant increment of $U_{50}$ with pressure for all the gap lengths involved. An increment of $31 \mathrm{kV}$ in $\mathrm{U}_{50}$ can be calculated for $2 \mathrm{~cm}$ and $3 \mathrm{~cm}$ gaps, whereas there is an increment of $25 \mathrm{kV}$ for the remaining gap lengths.

\begin{tabular}{ccc}
\multicolumn{2}{c}{ Table 1. Partial pressures of $\mathrm{CF}_{3} \mathrm{I}$ and $\mathrm{CO}_{2}$ gases for mixture ratio of $30 \%-70 \%$} \\
\hline $\begin{array}{c}\text { Total Pressure } \\
\text { (bar [abs]) }\end{array}$ & $\begin{array}{c}\text { Partial Pressure of } \mathrm{CF}_{3} \mathrm{I} \\
\text { (bar [abs]) }\end{array}$ & $\begin{array}{c}\text { Partial Pressure of } \mathrm{CO}_{2} \\
\text { (bar [abs]) }\end{array}$ \\
\hline 1.0 & 0.30 & 0.70 \\
1.5 & 0.45 & 1.05 \\
2.0 & 0.60 & 1.40 \\
\hline
\end{tabular}

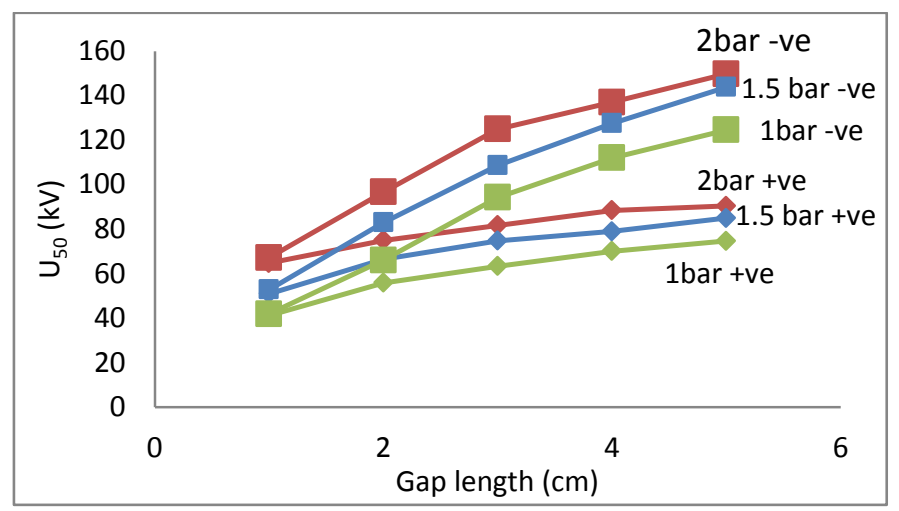

Figure 1. $\mathrm{U}_{50}$ curves for various pressures in relation to gap lengths

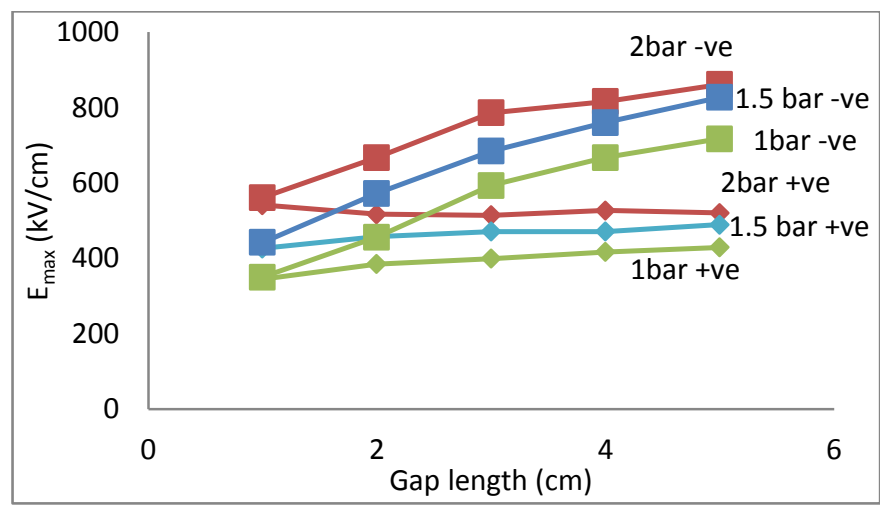

Figure 2. $\mathrm{E}_{\max }$ curves for various pressures in relation to gap lengths

However, under the positive impulse, the relative increase with pressure in $\mathrm{U}_{50}$ is seen to decrease from $1 \mathrm{~cm}$ to $5 \mathrm{~cm}$, with $23.5 \mathrm{kV}$ at $1 \mathrm{~cm}, 19 \mathrm{kV}$ at $2 \mathrm{~cm}$, and only $16 \mathrm{kV}$ at $5 \mathrm{~cm}$. Generally, it can be said that $\mathrm{U}_{50}$ curves for a $\mathrm{CF}_{3} \mathrm{I}-\mathrm{CO}_{2}(30 \%-70 \%)$ mixture in relation to gap length, under a rod-plane electrode configuration, are the same for a pressure of $1-2$ bar.

Since $U_{50}$ increases significantly with gap length under a rod-plane configuration (negative impulse polarity), which is true for all pressures studied, $\mathrm{E}_{\max }$ will also be increased according to $\mathrm{U}_{50}$ depicted in Figure 2. From $1 \mathrm{~cm}$ to $5 \mathrm{~cm}$, the increases in $\mathrm{E}_{\max }$ are $367 \mathrm{kV} / \mathrm{cm}$ for $1.0 \mathrm{bar}, 385 \mathrm{kV} / \mathrm{cm}$ for $1.5 \mathrm{bar}$, and $300 \mathrm{kV} / \mathrm{cm}$ for $2.0 \mathrm{bar}$. Considering the increase in $\mathrm{E}_{\max }$ in terms of percentage provides more interesting results: At 1.0bar of pressure, an increment of $105 \%$ in $\mathrm{E}_{\max }$ can be calculated, whereas for 1.5 and $2.0 \mathrm{bar}$, there are $87 \%$ and $53 \%$ increments in $\mathrm{E}_{\max }$ respectively. With this information, it can be noted that for 1.5 bar and from $1 \mathrm{~cm}$ to $5 \mathrm{~cm}$ gap, the increment in the absolute value of $\mathrm{E}_{\max }$ is higher than at 1.0bar. However, in terms of percentage, the increment is lower than that of $1.0 \mathrm{bar}$. 
Under a positive impulse, $\mathrm{E}_{\max }$ curves are almost flat throughout the gap length for all pressures. A slight increase can be observed at 1.0 and 1.5 bar, while a very small decrease is observed at 2.0bar. An increase in pressure will increase the $\mathrm{E}_{\max }$ value but the behaviour of the $\mathrm{E}_{\max }$ will be almost the same value for all the gap lengths for all pressures. In general, as with $\mathrm{U}_{50}$, it can be said that, for a $\mathrm{CF}_{3} \mathrm{I}_{-} \mathrm{CO}_{2}(30 \%-70 \%)$ gas mixture, $\mathrm{E}_{\max }$ curves are the same for pressures of $1-2 \mathrm{bar}$ in relation to gap length under a rod-plane electrode configuration.

\section{OBSERVATION ON SOLID BY-PRODUCTS OF $\mathrm{CF}_{3} I-\mathrm{CO}_{2}$ MIXTURES}

In this investigation, two samples of electrodes, the rod electrode and plane (ground) electrode have been studied to examine the solid by-products. Figure 3 and Figure 4 show the brownish material on each electrode. In all observations, the solid by-product is more likely to be deposited on the high voltage or energized electrode rather than the ground electrode. The pattern of the solid deposits on both high voltage and ground electrodes are very similar to the damage caused by dc corona in $\mathrm{SF}_{6}$ gas. Figure 3 shows the solid deposits are much clearer on the surface where the field line is the highest (near the tip of the rod), as explained by Yanallah and Pontiga [8]. This similarity with the dc corona effects has also been reported by Anis and Srivastava [9]. The pre-breakdown phenomena under observed under dc voltage is also generally true under impulse voltages [9].

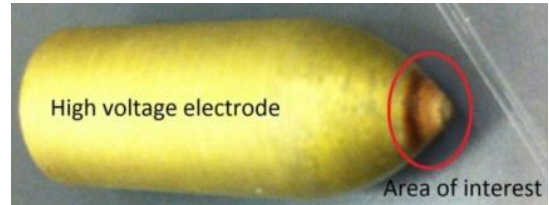

Figure 1. Solid by-products on rod electr

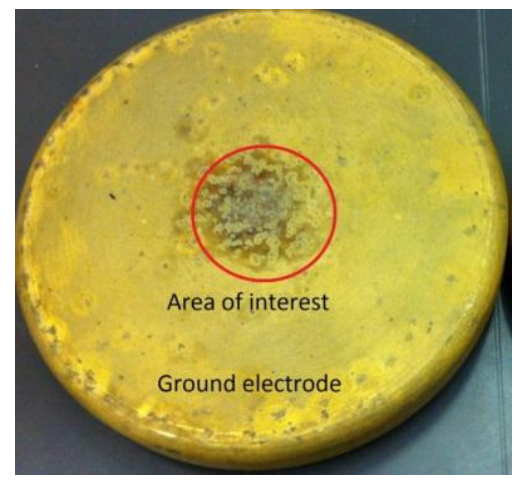

Figure 2. Solid by-products on plane ele

To analyse the solid by-product deposited on the electrodes, two methods are involved, image magnification is carried out using a Scanning Electron Microscope (SEM) and element analysis is done using an Energy Dispersive X-Ray (EDX) Spectrometer. By using these two methods, any element that exists on the surface of the electrodes can be analysed and confirmed.

Scanning electron microscope image for a rod electrode and plane electrode are shown in Figure 5 and Figure 6 respectively. The effects of sparkovers can be seen on both electrodes, in the form of rough surfaces.

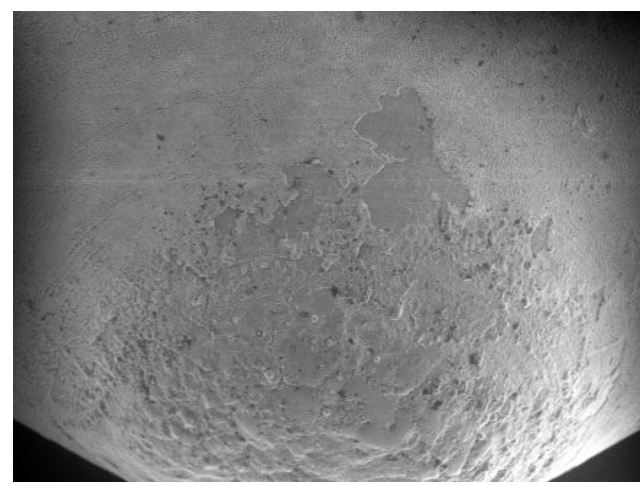

Figure 5. Electron image of rod electrode

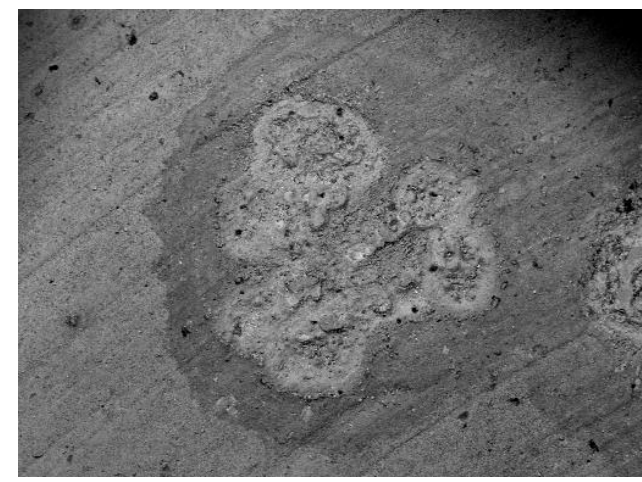

Figure 6. Electron image of plane electrode 
Figure 7 shows the spectrum analysis on the rod electrode, and Table 2shows the detected elements in the weight and atomic percentage. Meanwhile, Figure 8 and Table 3 show the results from the plane electrode analysis.

As can be seen from the figures and tables, both rod and plane electrodes contain iodine as the main element. More iodine is deposited on the rod electrode contributing as much as $53.80 \%$ of the overall weight, while on a plane electrode, iodine is contributing $41.74 \%$. If there is a solid dielectric between the high voltage electrode and ground electrode, iodine may deposit on the surface of the electrode and will significantly affect the insulation strength of the $\mathrm{CF}_{3} \mathrm{I}$ gas, as was reported by Takeda et al. [10], [11] .

Based on the above analysis, it is important that efforts towards reducing the amount of iodine are carried out to ensure the insulation strength of the $\mathrm{CF}_{3} \mathrm{I}$ gas and its mixtures are kept at the highest level. Other distinctive elements detected by the EDX include carbon and oxygen, which come from $\mathrm{CO}_{2}$ gas, as well as copper and zinc, which are the elements in the electrode material consisting of brass.

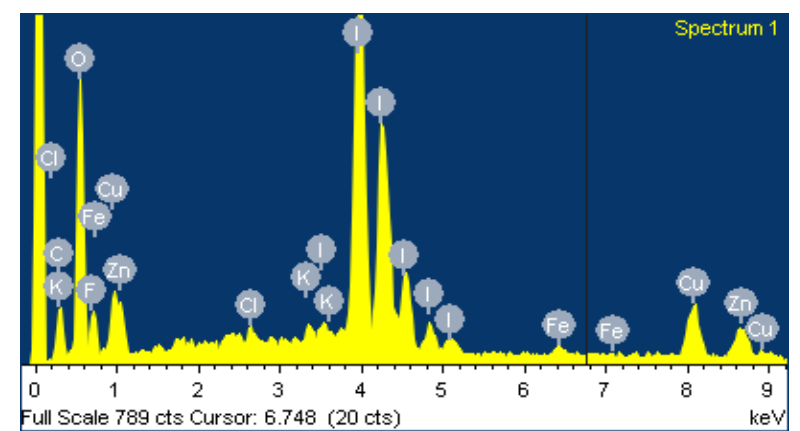

Figure 7. EDX spectrum on a rod electrode

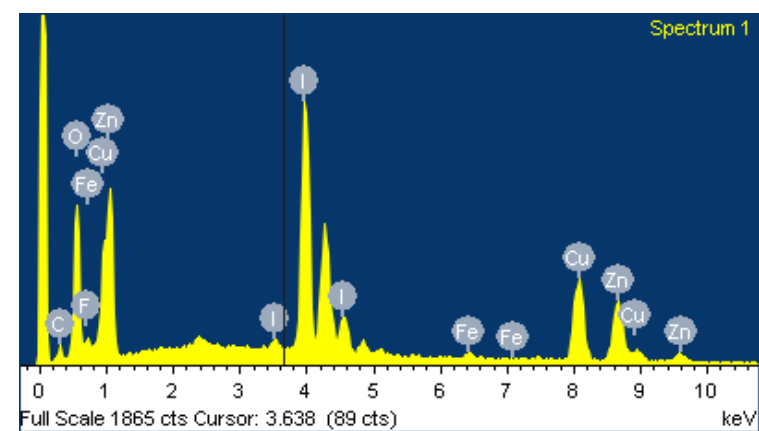

Figure 8. EDX spectrum on a plane electrode

Table 2. Element analysis from an EDX spectrum on a rod electrode

\begin{tabular}{lcc}
\hline Element & Weight\% & Atomic\% \\
\hline Carbon $(\mathrm{C})$ & 6.62 & 22.11 \\
Oxygen $(\mathrm{O})$ & 13.54 & 33.98 \\
Fluorine $(\mathrm{F})$ & 6.80 & 14.37 \\
Chlorine $(\mathrm{Cl})$ & 0.48 & 0.54 \\
Potassium $(\mathrm{K})$ & 0.53 & 0.54 \\
Iron $(\mathrm{Fe})$ & 0.81 & 0.59 \\
Copper $(\mathrm{Cu})$ & 9.73 & 6.15 \\
Zinc $(\mathrm{Zn})$ & 7.69 & 4.72 \\
Iodine $(\mathrm{I})$ & 53.80 & 17.01 \\
Totals & 100 & 100 \\
\hline
\end{tabular}

Table 3. Element analysis from an EDX spectrum on a plane electrode

\begin{tabular}{lcc}
\hline Element & Weight\% & Atomic\% \\
\hline Carbon $(\mathrm{C})$ & 3.97 & 15.96 \\
Oxygen $(\mathrm{O})$ & 10.93 & 32.98 \\
Fluorine $(\mathrm{F})$ & 1.46 & 3.71 \\
Iron $(\mathrm{Fe})$ & 0.71 & 0.61 \\
Copper $(\mathrm{Cu})$ & 21.54 & 16.36 \\
Zinc $(\mathrm{Zn})$ & 19.64 & 14.50 \\
Iodine $(\mathrm{I})$ & 41.74 & 15.87 \\
Totals & 100 & 100 \\
\hline
\end{tabular}

\section{CONCLUSION}

This investigation concludes that higher pressures of $\mathrm{CF}_{3} \mathrm{I}-\mathrm{CO}_{2}$ mixtures provide better insulation strength. The study in the rod-plane electrode configuration shows that $\mathrm{U}_{50}$ and $\mathrm{E}_{\max }$ curves along the increasing gap length are the same in accordance with the impulse polarity. However, a smaller standard deviation is observed and calculated for higher pressure, particularly under a positive impulse polarity. Observation on solid by-products of $\mathrm{CF}_{3} \mathrm{I}-\mathrm{CO}_{2}$ gas mixtures reveals that iodine is deposited on the electrode along with carbon and oxygen. However, iodine is more of a concern as it takes around 50\% of the total 
weight of the by-products and has been proven to affect the insulation strength of $\mathrm{CF}_{3} \mathrm{I}$ gas mixtures by previous research.

\section{ACKNOWLEDGMENTS}

The authors wish to thank Ministry of Higher Education (MOHE), Malaysia for the approved Fundamental Research Grant Scheme (FRGS) vote number 1531.

\section{REFERENCES}

[1] Y. Qiu and E. Kuffel, "Comparison of $\mathrm{SF}_{6} / \mathrm{N}_{2}$ and $\mathrm{SF}_{6} / \mathrm{CO}_{2}$ Gas Mixtures as Alternatives to $\mathrm{SF}_{6}$ Gas," IEEE Trans. Dielectr. Electr. Insul., vol. 6, no. 6, pp. 892-895, 1999.

[2] Y. Qiu and Y. P. Feng, "Investigation of $\mathrm{SF}_{6}-\mathrm{N}_{2}, \mathrm{SF}_{6}-\mathrm{CO}_{2}$ and $\mathrm{SF}_{6}$-Air as Substitutes for $\mathrm{SF}_{6}$ Insulation," in IEEE International Symposium on Electrical Insulation, 1996, no. 2, pp. 766-769.

[3] M. Hikita, S. Ohtsuka, S. Okabe, and S. Kaneko, "Insulation Characteristics of Gas Mixtures including Perfluorocarbon Gas," IEEE Trans. Dielectr. Electr. Insul., vol. 15, no. 4, pp. 1015-1022, 2008.

[4] M. Hikita, S. Ohtsuka, S. Okabe, and G. Ueta, "Breakdown Mechanism in $\mathrm{C}_{3} \mathrm{~F}_{8} / \mathrm{CO}_{2}$ Gas Mixture under NonUniform Field on the Basis of Partial Discharge Properties," IEEE Trans. Dielectr. Electr. Insul., vol. 16, no. 5, pp. 1413-1419, Oct. 2009.

[5] K. Mochizuki, T. Ueno, H. Mizoguchi, S. Yanabu, S. Yuasa, and S. Okabe, "Evaluation of Interruption Capability on Various Gases," in Gaseous Dielectrics X, L. G. Christophorou, J. K. Olthoff, and P. Vassiliou, Eds. New York: Springer Science + Business Media, Inc., 2004, pp. 265-270.

[6] L. Chen, P. Widger, M. Kamarudin, H. Griffiths, and A. Haddad, " $\mathrm{CF}_{3} \mathrm{I}$ Gas Mixtures: Breakdown Characteristics and Potential for Electrical Insulation," IEEE Trans. Power Deliv., vol. PP, no. 99, p. 1, 2016.

[7] European Committe for Electrotechnical Standardization, "BS EN 60060-1 : 2010 BSI Standards Publication Highvoltage test techniques Part 1: General definitions and test requirements," 2010.

[8] K. Yanallah and F. Pontiga, "A Semi-Analytical Stationary Model of a Point-to-Plane Corona Discharge," Plasma Sources Sci. Technol., vol. 21, no. 4, 2012.

[9] H. Anis and K. Srivastava, "Pre-Breakdown Discharges in Highly Non-Uniform Fields in Relation to Gas-Insulated Systems," IEEE Trans. Electr. Insul., vol. EI-17, no. 2, pp. 131-142, Apr. 1982.

[10] T. Takeda, S. Matsuoka, A. Kumada, and K. Hidaka, "Sparkover and Surface Flashover Characteristics of $C_{3} I$ Gas under Application of Nanosecond Square Pulse Voltage," in 16th International Symposium on High Voltage Engineering, 2009, pp. 812-817.

[11] T. Takeda, S. Matsuoka, A. Kumada, and K. Hidaka, "Flashover Characteristics of $\mathrm{CF}_{3} I$ on the Dielectric Surface," in Proceedings of XVIII International Conference on Gas Discharges and Their Applications, 2010, pp. 268-271.

\section{BIOGRAPHIES OF AUTHORS}

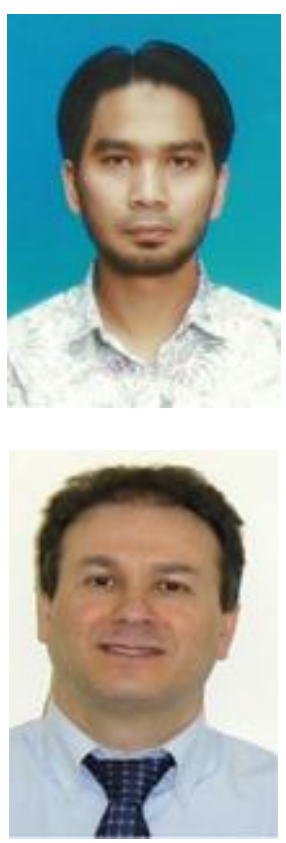

M. S. Kamarudin obtained his B.Eng. and M.Eng. Degrees in Electrical Engineering (Power) from Universiti Teknologi Malaysia (UTM) in 2003 and 2005, respectively, and a Ph.D. in High Voltage Engineering from Cardiff University, UK, in 2014. Currently, he is a senior lecturer in the Faculty of Electrical \& Electronic Engineering at Universiti Tun Hussein Onn Malaysia (UTHM). His research interests include gas discharges, high voltage surge arresters, and dielectrics and electrical insulation system. He is registered with the Board of Engineers Malaysia (BEM). He is also currently a member of IEEE and a graduate member of Institution of Engineers, Malaysia (IEM)

A. Haddad obtained a first degree in electrical engineering in 1985 and then a Ph.D. degree in high voltage engineering in 1990 . He is now a Professor in electrical engineering at Cardiff University with responsibility for research in high voltage engineering. His research interests are in overvoltage protection, insulation systems, insulation coordination and earthing of electrical energy systems. He has published an IET-Power Series Book on "Advances in High Voltage Engineering". He is a member of CIGRE working groups and a member of BSI PEL1/2, IEC TC37. He serves on the scientific committees of several international conferences. He is a Fellow of the IET. 


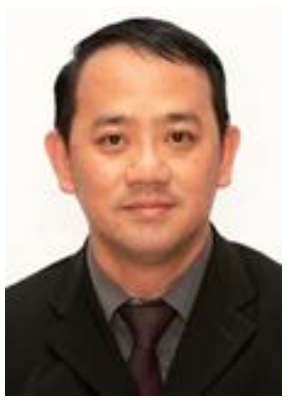

B.C. Kok obtained his B.Eng. (Electrical Engineering), M.Eng. (Power Systems), and Ph.D (Electrical Engineering) from Universiti Teknologi Malaysia (UTM) in 1998, 2002, and 2009, respectively. In 1998, he joined the Department of Engineering, Likom Technology Sdn. Bhd., as a product engineer. Between 2001 and 2004, he has joined TNB Research (TNBR) as research associate. Since 2004, he has been with the Department of Electrical Power Engineering, Universiti Tun Hussein Onn Malaysia (UTHM). He is currently serving UTHM as Associate Professor. His current technical interests include power system studies, renewable energy and energy harvesting systems and HVDC system modeling and simulation. He has worked on special HVDC control studies with TNBR from 2001 to 2002. He has published more than 50 publications in the fields of power systems and renewable energy systems. Since 1998, he has been registered with the Board of Engineers Malaysia (BEM). He is currently a member of IEEE and a graduate member of Institution of Engineers, Malaysia (IEM)

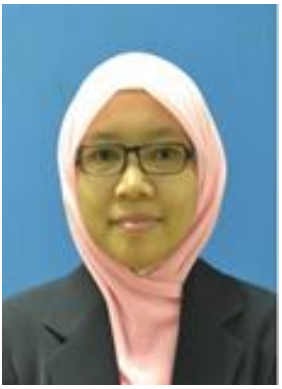

N. A. M. Jamail is a lecturer of Universiti Tun Hussein Onn Malaysia since 2008. She received the Bachelor degree in Electrical Engineering from Universiti Teknologi Malaysia in 2005, M.Eng in Power System from Universiti Tun Hussein Onn Malaysia in 2007 and Ph.D. in High Voltage Engineering from Universiti Teknologi Malaysia, in 2015. Her research interests include condition monitoring of polymer nanocomposite insulation for $\mathrm{HV}$ purpose, dielectrics and electrical insulation. She is registered with the Board of Engineers Malaysia (BEM). 